\title{
Developing a Novel Interactive Colorectal Cancer Educational Session for First-Year Medical Students to Enhance Interest in Public Health
}

\author{
Roselande Marcellon ${ }^{1} \cdot$ Katherine Donovan $^{1} \cdot$ Helen Zhou $^{1}$ - Shane Fiust-Klink ${ }^{1}$ - William Calawerts ${ }^{1} \cdot$ Mihir Patel $^{1}$. \\ Olivia Watman ${ }^{1}$ - David Miller ${ }^{1}$. Paul Sorum ${ }^{2}$. Kallanna Manjunath ${ }^{3} \cdot$ Rebecca Stetzer $^{4}$. Danielle Wales ${ }^{2}$. \\ Hyacinth Mason ${ }^{1} \cdot$ Michael Waxman $^{1} \cdot$ Heather Dacus $^{5} \cdot$ Paul Feustel $^{6} \cdot$ Michael Tadros $^{7}$
}

Accepted: 4 September 2021 / Published online: 22 September 2021

(c) American Association for Cancer Education 2021

\begin{abstract}
Medical students need more exposure to and a greater understanding of their role in public health throughout their training, which may influence more of them to pursue careers in public health or change how they practice medicine in the future. A novel colorectal cancer education session was created for first year medical students to attempt to increase public health interest, improve colorectal cancer knowledge and discuss barriers to colorectal cancer screening. We constructed a novel integrated interactive peer led colorectal cancer educational session of panelists with a wide range of experiences in colorectal cancer and colorectal cancer screening. The session involved a didactic component, case presentation, and group exercises followed by assembly discussion. We surveyed first-year medical students over two consecutive years to assess their interest in public health, knowledge of colorectal cancer, and perceptions of barriers to colorectal cancer screening before and after the educational session. We also evaluated student satisfaction with the session. We compared the pre- and post-survey results to assess for changes in interest, knowledge and perceptions. $74.63 \%$ of students in 2018 and $67.7 \%$ in 2019 evaluated the session as excellent or good, with knowledge regarding colorectal cancer screening markedly increased after the educational session. Students reported knowledge and access to healthcare among the biggest patient barriers to colorectal cancer screening. Interest in public health increased by 7.5\% and 5.6\% in 2018 and 2019, respectively. The implementation of this interactive educational peer led exercise can increase interest in public health, improve knowledge of colorectal cancer prevention and facilitate discussions of colorectal cancer screening barriers. We hope to encourage other programs to adopt this preliminary model.
\end{abstract}

Keywords Medical education $\cdot$ Public health $\cdot$ Colorectal cancer screening

\section{Introduction}

While medical education focuses much time on teaching students the intricacies of pathophysiology and treatment, there is limited focus on public health and preventive medicine. Only $33.7 \%$ of US medical school graduates from 2006 to 2008 felt that their education in public health was adequate [1]. Training future physicians who will understand the social determinants of health and the importance of public health measures such as cancer screening is essential to the health of the general population-these future physicians will be more likely to follow evidence-based

Michael Tadros

tadrosm1@amc.edu

Extended author information available on the last page of the article guidelines for recommended preventive interventions. It is important to raise awareness to these matters early on and build upon them throughout the four years of medical school and beyond.

The 2010 "Patients and Populations: Public Health in Medical Education" conference discussed the barriers and potential methods of integrating public health into medical school curricula. Public health topics were cited as lower in priority than other topics and less rigorous. Student barriers included limited understanding of cancer screening and public health and its relevance to practicing medicine as well as limited exposure to role models [2]. Although interest in public health among graduating medical students over the years has increased [3], there may still be a gap in understanding among entering physicians about their role in public health. Therefore, fostering deliberate education 
in public health among medical students early in their training may enhance their understanding of their role in public health practice and increase interest in engaging in public health activities.

Our study focuses on exposing medical students early on-in their first year-to colorectal cancer (CRC) screening and prevention. We developed a 90-min education session to help emphasize the importance of CRC screening and facilitate understanding of patient, physician, healthcare system, and community barriers to first year medical students. This education session is unique in its engagement of medical students in their pre-clinical years to address CRC and improve CRC screening rates as most national efforts are largely targeted at physicians and patients. In addition, the education session involves important discussions around contemporary and historical issues of CRC screening, disparities, and barriers as well as builds on efforts to increase participation in national campaigns to address CRC and improve CRC screening rates. Our method addresses the student barriers of understanding and appreciating public health early on and exposes them to a panel of role models who are either experts in public health or medical providers who have directly experienced and combatted the barriers to care their patients face.

We implemented a medical education program to increase medical student awareness in public health issues such as barriers to care and perhaps influence a change in practice when they are licensed physicians. In this study, we evaluated our model by analyzing participating students' knowledge and interest in public health by administering surveys before and after the educational program.

\section{Methods}

This was a mandatory session occurring on the first day of the Gastrointestinal Systems I Theme course at the medical college for first year medical students of the class of 2021 and then, in the following year, the class of 2022. Students learn about the physiology, pathology, pharmacology, and clinical disease courses of the gastrointestinal system in a standard lecture presentation format.

\section{Educational Program}

A 90-min educational session on CRC screening was conducted and consisted of a presentation, small group breakout session, and panel discussion (Fig. 1). First year medical students participating in the two consecutive years was $n=140$ in 2018 and $n=141$ in 2019. In both years, we allotted $30 \mathrm{~min}$ for presentation, $30 \mathrm{~min}$ for group work, and $30 \mathrm{~min}$ for panel discussion. The day before the session, students were given a brief education guide document outlining the epidemiology of CRC, the goal of screening along with various methods of screening, and general information on barriers identified in literature to screening categorized into patient, provider, healthcare system, and community factors. A five-question pre-session survey was sent to students to complete approximately $10 \mathrm{~min}$ prior to the start of the didactic session. The educational intervention proposed was evaluated using the TIDieR checklist (Appendix Table 1) [4].

\section{Didactic Session}

The session began with an introduction of panelists, including physicians from multiple specialties like preventive medicine, gastroenterology, family medicine, pediatrics, internal medicine, and geriatric medicine. Other panelists included speakers from the New York State Department of Health (NYSDOH), Better Health for Northeast New York (BHNNY), Bureau of Cancer Prevention and Control, and a member of the National Colorectal Cancer Roundtable. The Gastrointestinal Systems Associate Theme Director and a Preventive Medicine physician moderated the panel. This brief introduction was followed by a short case presentation about the real-life implications of timely colorectal cancer screening, and a lecture highlighting the epidemiology of colon cancer in New York state, screening methods, and barriers to screening. These barriers were divided

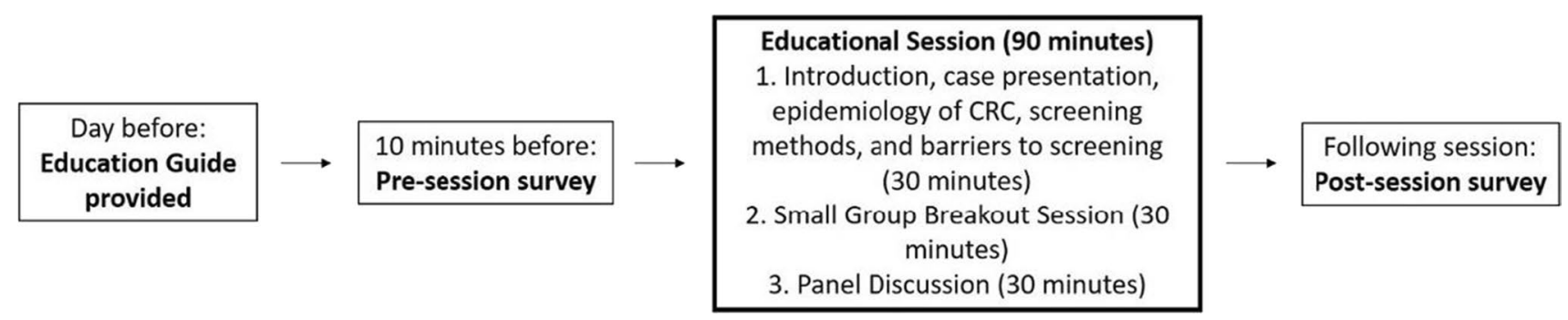

Fig. 1 Proposed timeline of educational session for medical students 
Table 1 Summary of correct responses pre and post-education session by year

\begin{tabular}{|c|c|c|c|c|c|c|c|}
\hline \multirow[t]{2}{*}{ Survey question } & \multirow[t]{2}{*}{ Correct response } & \multicolumn{3}{|l|}{2018} & \multicolumn{3}{|l|}{2019} \\
\hline & & $\begin{array}{l}\% \text { Pre } \\
(95 \% \text { CI) }\end{array}$ & $\begin{array}{l}\% \text { Post } \\
(95 \% \text { CI) }\end{array}$ & $\%$ Change & $\begin{array}{l}\% \text { Pre }(95 \% \\
\text { CI) }\end{array}$ & $\begin{array}{l}\% \text { Post } \\
(95 \% \text { CI) }\end{array}$ & $\begin{array}{l}\% \\
\text { Change }\end{array}$ \\
\hline $\begin{array}{l}\text { What is the } \\
\text { best method } \\
\text { for screening } \\
\text { for colorectal } \\
\text { cancer? }\end{array}$ & $\begin{array}{l}\text { Any CRC screen- } \\
\text { ing method as } \\
\text { long as it is done }\end{array}$ & $20.0 \%(9.4-30.6 \%)$ & $\begin{array}{l}56.1 \% \\
(40.8-71.4 \%)\end{array}$ & $36.1 \%$ & $35.1 \%(9.2-61.1 \%)$ & $\begin{array}{l}81.5 \% \\
(66.9-96.1 \%)\end{array}$ & $46.4 \%$ \\
\hline $\begin{array}{l}\text { According to } \\
\text { the American } \\
\text { Gastroentero- } \\
\text { logical Asso- } \\
\text { ciation, low-risk } \\
\text { patients should } \\
\text { be screened at } \\
50 \text { years of age. } \\
\text { What percent- } \\
\text { age of these } \\
\text { patients do you } \\
\text { think actually get } \\
\text { colorectal cancer } \\
\text { screening? }\end{array}$ & $\begin{array}{l}\text { More than } 50 \% \\
\text { but less than } 75 \%\end{array}$ & $7.3 \%(0.4-14.2 \%)$ & $\begin{array}{l}27.5 \% \\
(13.7-41.3 \%)\end{array}$ & $20.2 \%$ & $8.1 \%(0-16.9 \%)$ & $\begin{array}{l}59.3 \% \\
(40.8-77.8 \%)\end{array}$ & $51.2 \%$ \\
\hline $\begin{array}{l}\text { According to } \\
\text { the American } \\
\text { Gastroentero- } \\
\text { logical Asso- } \\
\text { ciation, low-risk } \\
\text { patients should } \\
\text { be screened at } \\
50 \text { years of age. } \\
\text { What is the } \\
\text { proposed target } \\
\text { for screening for } \\
\text { colorectal cancer } \\
\text { that providers } \\
\text { should achieve? }\end{array}$ & $80 \%$ & $\begin{array}{l}29.1 \% \\
(17.1-41.1 \%)\end{array}$ & $\begin{array}{l}73.2 \% \\
(59.5-86.9 \%)\end{array}$ & $44.1 \%$ & $\begin{array}{l}32.4 \% \\
(17.3-47.5 \%)\end{array}$ & $\begin{array}{l}77.8 \% \\
(62.1-93.5 \%)\end{array}$ & $45.4 \%$ \\
\hline
\end{tabular}

into four major categories: patient factors, provider factors, healthcare system factors, and community/population-based factors.

\section{Small Group Work}

Students were divided into small groups, provided a group worksheet exercise, and assigned to one of the four categories of factors (patient, provider, healthcare system, and community). Each group was given some time to brainstorm a potential project to address that particular barrier. After deliberation by upperclassmen student assistants and the theme leader, one project from each category was selected for presentation to the entire class along with a short summary of some other projects under that factor category. Panelists gave feedback for each project presented and shared their experiential knowledge of projects that have been implemented, their feasibility, and effectiveness.

\section{Survey Instrument Development}

In order to assess the effectiveness of the educational session, first year students who participated in the 2018 and 2019 sessions were provided a pre- and post-session survey regarding their knowledge about CRC screening. The surveys were voluntary, anonymous, and submitted online through a secure interface, Qualtrics, an online survey software tool licensed by Albany Medical College. The study was approved by the Albany Medical Center Committee on Research Involving Human Subjects Institutional Review Board.

Questions in the survey were selected based on the objectives outlined for the educational session. Each question was 
formed to assess medical student understanding of basic CRC screening knowledge before and after the session. We categorized survey questions into three major categories: Public health interest (question 1), knowledge (questions 2, 4, and 5), and patient barriers (question 3) (Appendix). Most questions were multiple choice; one question was formatted using a 4-point Likert scale (very likely, likely, unlikely, not sure), and another question used free response text (available only in the post-session survey). The survey questions included the following:

(1) How likely are you to pursue further education in public health after or during medical school? (MPH, residency, fellowship, certificate program)

(2) What is the best method for screening for colorectal cancer?

(3) What do you believe is the biggest patient barrier to colorectal cancer screening?

(4) According to the American Gastroenterological Association, low-risk patients should be screened at 50 years of age. What percentage of these patients do you think actually get colorectal cancer screening?

(5) What is the proposed target for screening set by the American Gastroenterological Association for lowrisk patients for colorectal cancer that providers should achieve?

\section{Sampling and Survey Implementation}

Student responses to the pre- and post-survey questions were compared. Students were asked to provide comments about the program as well as recommend ways the educational session could be improved (available in the post-session survey only). Students were also given an opportunity at the end of the course theme to rate and provide feedback on the education session in the final course evaluation.

\section{Data Analysis Plan}

The responses to the survey are reported as a percentage of the total responses. We used Qualtrics to store and extract the anonymous pre- and post-survey data from each year the session was conducted. Pre- and post-session responses were tested for significant differences using a Chi-square test. Differences in pre- and post- survey responses regarding students' likelihood to pursue further training in public health, baseline knowledge about CRC screening methods, and screening targets were analyzed. We used a pragmatic sample size consisting of each student who participated in the program with an anticipated response rate of $30 \%$, which is a typical survey response rate when no incentive is given [5].

\section{Results}

\section{Baseline Characteristics}

Over the two academic years, approximately 280 students participated in the educational sessions. We obtained a total of 160 survey responses over the two-year period. Survey response rates for the pre-workshop ranged from approximately $39.28 \%(n=55)$ in the first year (2018) of the education session to $26.24 \%(n=37)$ in the second year (2019). Response rates for the post-workshop survey were $29.29 \%$ $(n=41)$ and $19.15 \%(n=27)$ in the first and second year of the education session, respectively. Attrition rates within years when comparing the number of respondents in the pre- and post-survey had averages of $31.22 \%$ in 2018 and $37.04 \%$ in 2019 (Appendix, Table 2).

\section{Public Health Interests}

In the first year of the educational session ( $2018 ; n=55$ pre, $n=41$ post), approximately $29.09 \%$ of students reported that they were very likely or likely to pursue further education in public health after or during medical school (e.g., earn an $\mathrm{MPH}$, obtain training in public health during residency or in fellowship, or pursue a certificate program) prior to the educational session. In the second year (2019; $n=37$ pre, $n=27$ post), approximately $35.14 \%$ of students indicated that they were likely to pursue further education in public health after or during medical school prior to the educational session. Following the education session, the percentage of students reporting they were very likely or likely to pursue further education in public health after or during medical school increased to $36.59 \%$ and $40.74 \%$ in the first and second year of the educational session respectively (Fig. 2).

Approximately $38.18 \%$ and $35.14 \%$ of students, in the first and second year respectively, indicated that they were unlikely to pursue further education in public health after or during medical school prior to the educational session. Following the educational session, the number of students who responded that they were unlikely to pursue further education in public health after or during medical school was $31.71 \%$ and $29.63 \%$ for the first and second year, respectively (Fig. 2).

\section{Knowledge}

The first knowledge category question in the survey (question 2) asked students to identify the best method for screening for colorectal cancer. Students were given the following choices to select from: colonoscopy, sigmoidoscopy, fecal occult blood test, and any CRC screening method as long it 
Fig. 2 Public health interest. Student responses to survey question on likeliness to pursue further education in public health during or after medical school before and after the educational session in 2018 and 2019

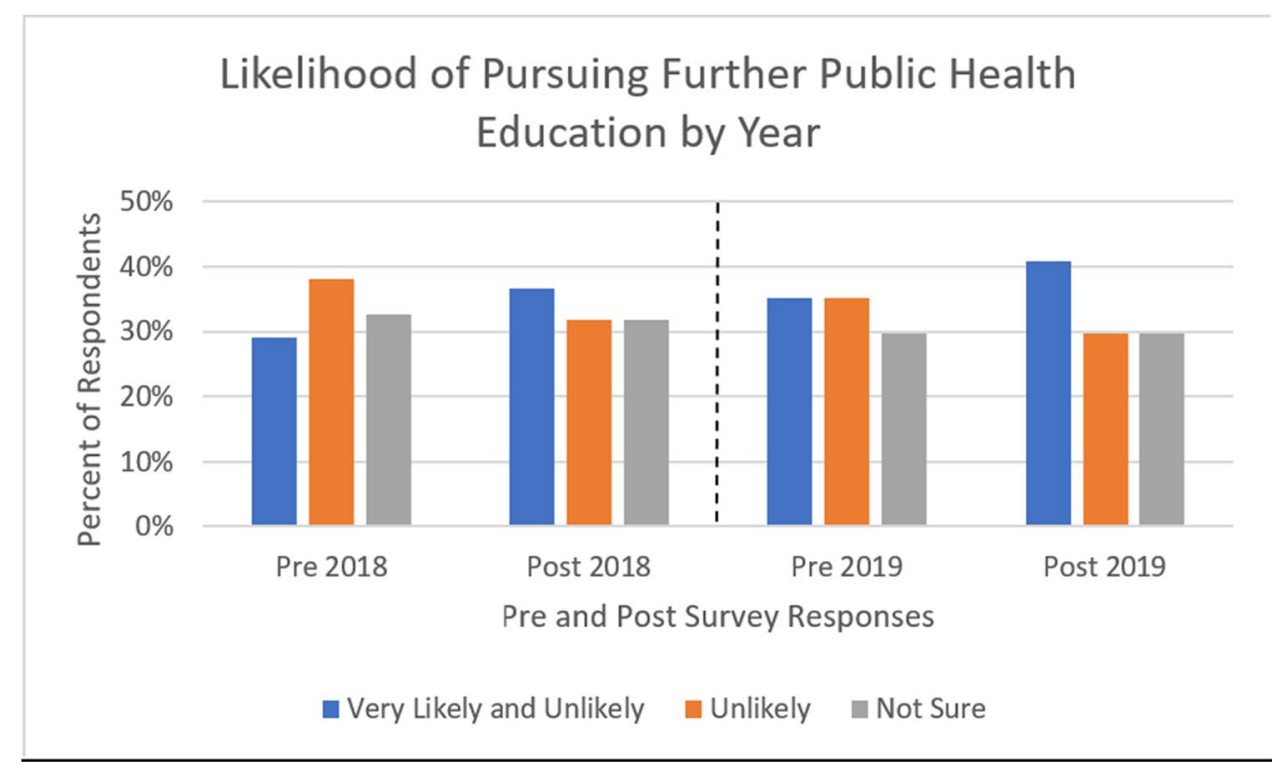

is done; the correct answer is the latter choice, any method as long it is done. In the first year (2018: $n=55$ pre, $n=41$ post) of the education session, $74.55 \%$ of students initially indicated that colonoscopy was the best method for CRC screening and 20\% (95\% CI 9.4-30.6\%) chose the correct answer of any method. After the education session, $56.1 \%$ (95\% CI 40.8-71.4\%) answered correctly. In the second year (2019; $n=37$ pre, $n=27$ post), $64.86 \%$ of students indicated colonoscopy was the best screening method before the education session, while $35.14 \%$ (95\% CI 19.7-50.5\%) chose correctly. Following the education session, $18.52 \%$ of students indicated colonoscopy was the best method for CRC screening, while $81.48 \%$ (95\% CI 66.9-96.1\%) answered all methods. The absolute change observed in the first year (2018) among students selecting the correct answer in the pre- $(20.00 \%)$ compared to the post-survey $(56.10 \%)$ represents an increase of $36.10 \%$. Similarly, in the second year (2019), the change observed among students selecting the correct answer between the pre $(35.14 \%)$ and post-survey $(81.48 \%$ ) represents an increase of $46.35 \%$ (Table 1 ).

The second question in the knowledge category of the survey (question 4) asked students to identify the percentage of low-risk patients who get screened for colorectal cancer. Students were able to select from the following choices: $25 \%$ or less (choice worded as $22 \%$ or less in the 2018 survey), between 25 and $50 \%$, more than $25 \%$ but less than $75 \%$, greater than $75 \%$ but less than $100 \%$, and $100 \%$. The correct answer for this survey question is more than $50 \%$ but less than $75 \%$. In the first year of the education session (2018; $n=55$ pre, $n=40$ post), $7.27 \%$ (95\% CI $0.4-14.2 \%$ ) of students selected the correct answer, and this number increased to $27.50 \%$ (95\% CI 13.7-41.3\%) following the session. In the second year of the education session $(2019 ; n=37$ pre, $n=27$ post), $8.11 \%$ (95\% CI 0-16.9\%) of students selected the correct choice prior to the session, and this number increased to $59.26 \%$ (95\% CI 40.8-77.8\%) after the session. Most student respondents indicated that screening rates were less than $50 \%$ (combined responses for less than $22 \%$ or $25 \%$ and between 25 and 50\%) among low-risk patients in the first $(92.73 \%)$ and second $(91.88 \%)$ years before the education session; following the education session, students selecting this choice decreased by $25.23 \%$ and $54.84 \%$ for the first and second year respectively (Table 1).

The third question in the knowledge category of the survey (question 5) asked students to identify the proposed target for providers set by the American Gastroenterological Association for colorectal cancer screening among low-risk patients. Students were able to select from the following choices: $0 \%, 20 \%, 40 \%, 60 \%, 80 \%$, and $100 \%$. The correct answer for this survey question is $80 \%$. In the first year of the education session ( $2018 ; n=55$ pre, $n=41$ post), most students $(38.18 \%)$ selected $100 \%$ as the proposed target. Following the education session, most students were able to correctly identify the proposed target $(73.17 \%, 95 \% \mathrm{CI}$ $59.5-86.9 \%$ ). Similarly, in the second year of the education session ( $2019 ; n=37$ pre, $n=27$ post), most students (37.84\%) in the pre-survey chose $100 \%$ as the proposed target for providers. Following the education session, most students $(77.78 \%, 95 \%$ CI 62.1-93.5\%) were able to identify the correct proposed screening target of $80 \%$ set by the American Gastroenterological Association (Table 1).

\section{Patient Barriers}

Students were asked to select what they felt was the biggest patient barrier to CRC screening and given the following choices identified in literature: knowledge, fear, motivation, access to healthcare, cultural boundaries, or other. In the 
first year of the education session (2018; $n=46$ pre, $n=39$ post), most students chose access to healthcare $(41.30 \%)$, fear $(30.43 \%)$, and knowledge (21.74\%) among the biggest patient barriers to CRC screening. After the education session, the numbers shifted and students identified knowledge (38.46\%), fear (28.21\%), and access to healthcare (17.95\%) as the biggest patient barriers to CRC screening. In the second year (2019; $n=37$ pre, $n=27$ post) of the education session that was conducted, most students selected access to healthcare (48.65\%), knowledge (32.43\%), and fear (16.22\%) for the biggest patient barriers to CRC screening prior to the session. After the session, students' responses changed in a similar fashion as in the first year with knowledge $(62.96 \%)$ chosen as the biggest patient barrier, followed by access to health care $(14.81 \%)$ and fear $(11.11 \%)$.

At the end of the course theme each year, students are asked to submit an evaluation related to how they rated the session and give feedback. Students are given the following selection options for ratings: excellent, good, average, fair, and poor. Most students rated the education session as excellent or good $(2018 ; n=134,74.63 \%$ and $2019 ; n=130$, $67.69 \%)$.

\section{Discussion}

Our introductory educational session for first year medical students on colorectal cancer screening was effective in meeting the objectives of enabling students to identify the overall goal of screening, colorectal cancer screening methods, current screening rates among low-risk patients and the American Gastroenterological Association proposed target for colorectal cancer screening for providers. Analysis of the pre- and post-survey responses demonstrated a positive change in knowledge surrounding colorectal screening rates, targets, and methods and increase in public health interest. Students' perception of patient barriers also indicated improved knowledge between the pre- and postsurveys indicating that this may be a potential area where they - throughout their medical training and as future practitioners-can play an important role in informing patients about the importance of screening and its feasibility. The positive shifts observed between the pre- and post-surveys in the areas of public health interest and knowledge categories provide impressive exploratory points which warrant further investigation, perhaps in a more longitudinal manner, to examine how this form of early engagement of medical students increases public health interest and related activities, as well as impacts outcomes such as overall screening rates for colorectal cancer.

Strengths of our educational session study include our use of multiple media forms to convey information to students; these entailed a combination of case presentation, lecture, expert panel, and interactive group work in order to enhance the learning experience. Our design enabled real-time student feedback and input, as well as immediate evaluation of our education session. Students overwhelmingly reported high rates of satisfaction with the education session; most students rated the session as an excellent or good activity. Future research is needed to help elucidate the effect and impact of early exposure to public health in medical education and training on career choices and patient care decisions. Also, longer-term studies are needed to assess how early engagement and exposure affects knowledge, behavior, and future career perceptions.

\section{Limitations}

We are aware of several limitations with our study including our low survey response rates for our pre- and post-surveys, and our small sample size as a result. In addition, time constraints related to our expert panel availability and the need for a dedicated group of student volunteers to help facilitate aspects of the session might have affected the session experience. The narrow composition of our panel (only physicians) limited our ability to explore and demonstrate crossfunctionality of inter-professional relations, a key element in public health work.

Further, the survey used was limited in nature of its ability to capture in depth information due to the short number of questions as well as type of questions included; this served to limit the amount of data available for analysis as well as the types of analyses we could perform. The use of more and in-depth survey questions, however, will have to be weighed against survey feasibility as more questions run the risk of becoming time consuming and which can lead to a lower likelihood of completion. Lastly, our education session was designed specifically for first year medical students, but the material can be adapted for use among other groups of health professionals at varying levels. The COVID-19 pandemic placed further barriers in our ability to continue these educational sessions for subsequent classes. We are exploring options to adapt this model into a virtual format.

\section{Conclusion}

We believe that our educational session helped facilitate an appreciation and understanding among medical students of the importance of cancer screening and prevention and their role in public health engagement. This educational session demonstrates that knowledge, public health interest, and related activities can be improved in a relatively short time frame. Also, our educational session has enabled discussions about barriers to CRC screening and ways to improve these rates based on perceived barriers to occur much earlier 
in a medical student's training. Importantly, this model can be easily applied to programs at other medical schools. We believe that informing future physicians about these issues, reminding them of their role in public health, and encouraging them now to collaborate and participate in current public health efforts are part of the fundamental work necessary to address low CRC screening rates and improve CRC outcomes.

Supplementary Information The online version contains supplementary material available at https://doi.org/10.1007/s13187-021-02087-y.

Data Availability Not applicable.

Code Availability Not applicable.

\section{Declarations}

Conflict of Interest The authors declare no competing interests.

\section{References}

1. Maeshiro R, Johnson I, Koo D, Parboosingh J, Carney JK, Gesundheit N et al (2010) Medical education for a healthier population: reflections on the Flexner Report from a public health perspective. Acad Med 85(2):211-219

2. Mahoney JF, Fox MD, Chheda SG (2011) Overcoming challenges to integrating public and population health into medical curricula. Am J Prev Med 41(4 Suppl 3):S170-S175

3. Koo K, Lapp I (2014) Educating the next generation of physicians in public health: the MPH for medical students. Public Health Rep 129(5):460-464

4. Hoffmann TC, Glasziou PP, Boutron I, Milne R, Perera R, Moher $\mathrm{D}$, et al. Better reporting of interventions: template for intervention description and replication (TIDieR) checklist and guide. Bmj-Brit Med J. 2014;348.

5. Brtnikova M, Crane LA, Allison MA, Hurley LP, Beaty BL, Kempe A. A method for achieving high response rates in national surveys of U.S. primary care physicians. PLoS One. 2018;13(8):e0202755.

Publisher's Note Springer Nature remains neutral with regard to jurisdictional claims in published maps and institutional affiliations.

\section{Authors and Affiliations}

\section{Roselande Marcellon ${ }^{1} \cdot$ Katherine Donovan $^{1} \cdot$ Helen Zhou $^{1} \cdot$ Shane Fiust-Klink ${ }^{1}$. William Calawerts ${ }^{1} \cdot$ Mihir Patel $^{1}$. Olivia Watman ${ }^{1} \cdot$ David Miller $^{1} \cdot$ Paul Sorum $^{2} \cdot$ Kallanna Manjunath $^{3} \cdot$ Rebecca Stetzer $^{4} \cdot$ Danielle Wales $^{2}$. Hyacinth Mason ${ }^{1} \cdot$ Michael Waxman $^{1} \cdot$ Heather Dacus ${ }^{5} \cdot$ Paul Feustel $^{6} \cdot$ Michael Tadros $^{7}$}

Roselande Marcellon

marcelr1@amc.edu

Katherine Donovan

donovak2@amc.edu

Helen Zhou

zhouh@amc.edu

Shane Fiust-Klink

fiustks@amc.edu

William Calawerts

William.calawerts@cuanschutz.edu

Mihir Patel

mihir199402@gmail.com

Olivia Watman

watmano@amc.edu

David Miller

millerd16@amc.edu

Paul Sorum

sorump@amc.edu

Kallanna Manjunath

manjunathk@amc.edu

Danielle Wales

walesd@amc.edu
Hyacinth Mason

masonh1@amc.edu

Michael Waxman

waxmanm@amc.edu

Heather Dacus

heather.dacus@health.ny.gov

Paul Feustel

feustep@amc.edu

1 Albany Medical College, Albany, NY 12208, USA

2 Department of Internal Medicine and Pediatrics, Albany Medical Center Hospital, Albany , NY 12208, USA

3 Better Health for Northeast New York PPS, Albany, NY 12208, USA

4 Department of Family and Community Medicine, Albany Medical Center Hospital, Albany , NY 12208, USA

5 New York State Department of Health, Albany, NY 12204, USA

6 Department of Neuroscience and Experimental Therapeutics, Albany Medical College, Albany, NY 12208, USA

7 Department of Gastroenterology, Albany Medical Center Hospital, Albany, NY 12208, USA 